\title{
Innovative Interpretive Qualitative Case Study Research Method Aligned with Systems Theory for Physiotherapy and Rehabilitation Research: A review of the methodology
}

\author{
Chetty, L. \\ National Health Service, London, United Kingdom \\ Correspondence \\ Laran Chetty•laranchetty@gmail.com
}

\begin{abstract}
SUMMARY
The aim of this paper is to review the methodology for interpretive qualitative case study research method using systems theory. The paper also addresses the underlying assumptions of this research methodology and how these affect the way research questions are answered. In reviewing this methodology, an example is provided so that more physiotherapy researchers and clinicians can adopt this approach in their work.
\end{abstract}

KEYWORDS: qualitative, interpretive, case study, systems theory, methodology

\section{INTRODUCTION}

The combined use of case study and systems theory is rarely discussed in the literature. The use of both approaches enables the specifics of the case to be considered with the influence of the broader systems. This offers in-depth analysis of the case in the context of the system (Anaf et al, 2007). Physiotherapy has many operating systems that are developed from organizational hierarchies, funding mechanisms and traditional service delivery. Systems theory is used to explore innovation, change and complexity in a service in the context of the case. The alignment of case study research with systems theory can increase the evidence base in physiotherapy and rehabilitation research by the nature of using such a detailed methodology.

The aim of this paper is to review the research methodology for aligning an innovative, interpretive qualitative case study research method with systems theory to advance physiotherapy and rehabilitation research. This paper also addresses the underlying assumptions of this research methodology and how these affect how research questions are answered. An example is provided in order to demonstrate this methodology in practice.

\section{RATIONALE FOR USING A QUALITATIVE DESIGN} The purpose of qualitative research is to understand the meaning that people attribute to their experiences in the social world within a specific context or situation (Angen, 2000; Denzin and Lincoln, 2003). The underlying philosophical assumption of qualitative research is that truth and reality are not absolute (Jones et al, 2006). Qualitative research does not seek to describe a particular norm, but rather to discover the richness and complexity of a situation which may be different from the norm resulting in contextually framed perspectives (Manning, 1992).

In qualitative research, the researcher is part of the process of discovering meaning and so there is an appreciation of subjectivity and a need for reflexivity on the part of the researcher (Flick, 2002). This is in contrast to quantitative research that aims to eliminate the researcher from the research process, so that the data can be analysed in a bias-free and objective manner in order to discover a single truth (Lee and Baskerville, 2003). Qualitative research is continually developing and evolving, moving from grand narratives to the rich and in-depth descriptions of meaning, feelings and experiences (Roulston et al, 2003). Although the increase in evidence-based practice encourages a quantitative approach to research (Darling and 
Interpretive Qualitative Case Study Aligned with Systems Theory for Physiotherapy and Rehabilitation Research

Scott, 2002), the main benefit of doing qualitative research is the patience, skill, creativity and time commitment needed in undertaking a research process that is continually evolving and the value it places on subjective viewpoints in exploring the research phenomenon more holistically (Irvine and Gaffikin, 2006).

Qualitative research is most appropriate as it crosscuts disciplines, fields and subject matters (Denzin and Lincoln, 2003, p.3). Qualitative research requires rapport and empathetic listening skills, which the researcher can use to build a bond of trust, care and understanding so that participants will be more willingly to provide honest and multiple explanations for their viewpoints (Manning, 1992).

\section{THE INTERPRETIVE FRAMEWORK}

The interpretive framework is a theoretical approach that involves the systematic analysis of socially meaningful action in order to arrive at an understanding and interpretation of how people create and maintain their social worlds (Neuman, 1997). According to Patton (2002) researchers risk losing a deeper understanding of the phenomenon by staying within a positivist framework that orientates towards generalizability.

Interpretivism is distinguished from positivism in that information is firmly located within the subjective epistemology (Greene, 1992). The pursuit of objectivity of research findings is virtually impossible given the subject selection of details the researcher chooses to report (Greene, 1992). According to Veenstra (1999), facts are fluid and embedded within a meaning system, they are not impartial, objective or neutral. Interpretivism acknowledges that social phenomena must be understood in the social contexts in which they are constructed and are guided by how people interpret and understand situations (Angen, 2000).

Using interpretivism means respecting its theoretical principles and using it to enhance the usefulness of the findings (Thorne et al, 1997). Interpretive research is strongest when it relies on robust data collection to make confident claims about shared and opposed views. However, this should not be at the expense of deeper meaning and insight (Thorne et al, 1997). Interpretivism encourages the researcher to be the main data collection tool as this enhances the consistency of data collection and it supports the researcher's engagement in the study (Parry, 1997). The researcher accepts participants' varying opinions as their truth as this forms the core of interpretive inquiry (Gergen, 2002). The researcher must minimize the feeling that his/her own thoughts are superior (Gergen, 2002). Participants should not be treated as mere objects or numbers, instead the researcher should focus on the individual's perspective (Gergen, 2002). The above theoretical principles of an interpretive approach reinforce the fact no absolute truths are expected to come from the research questions, only the pursuit of a through, holistic perspective of the phenomenon.

\section{CASE STUDY AS A RESEARCH METHOD}

Case study research allows for the exploration and understanding of complex issues. It can be considered a robust research method particularly when a holistic in-depth investigation is required (Gulsecen and Kubat, 2006). Case studies, in their true essence, explore and investigate contemporary real-life phenomena through detailed contextual analysis of events or conditions and their relationships. Yin (1994) defined case study research as an empirical inquiry that investigates a contemporary phenomenon within its real-life context when the boundaries between phenomenon and context are not clearly evident, and multiple sources of evidence are used.

Unlike quantitative analysis which analyses data at the macro level, case studies observe the data at the micro level. Crafting the design of case studies is of paramount importance. Researchers can adopt either a single-case or multiple-case study design depending on the phenomenon in question. A single-case design could be criticized for its inability to provide a generalizing conclusion, in particular when the events are rare. One way of overcoming this is by triangulating different sources of information (Creswell, 2003). Triangulation is defined as the combining of methods so that diverse viewpoints or standpoints can cast light upon a topic. This combining of data collection methods is generally thought to enhance the credibility of the findings (Creswell, 2003).

Yin (1994) notes three categories of case studies, namely: exploratory, descriptive, and explanatory. First, exploratory case studies are set to explore any phenomenon in the data which serves as a point of interest to the researcher. Second, descriptive case studies are set to describe the natural phenomena which occur within the data in question. The goal set by the researcher is to describe the data as they occur (McDonough and McDonough, 1997). Third, explanatory case studies examine the data closely 
both at the surface and at a deep level, in order to explain the phenomena in the data (Yin, 1994).

In addition, according to McDonough and McDonough (1997), other categories include interpretive and evaluative case studies. Through interpretive case studies, the researcher aims to interpret the data by developing conceptual categories, supporting or challenging the assumptions made regarding them. In evaluative case studies, the researcher goes further by adding their judgement to the phenomena found in the data. Yin (1994) cautions researchers against any attempt to separate these categories or to conceive them as a hierarchy. Yin (1994) postulates that a common misconception is that the various research strategies should be arrayed hierarchically. In defining case studies, another researcher (Stake, 1995) distinguishes three types: the intrinsic, the instrumental, and the collective. In an intrinsic case study, a researcher examines the case for its own sake. In an instrumental case study, the researcher aims to understand another case or another issue. In a collective case study, the researcher coordinates data from several different sources. Unlike intrinsic case studies which aim to solve the specific problems of an individual case, instrumental and collective case studies may allow for the generalization of findings (Stake, 1995).

There are a number of advantages in using case study as a research method. First, the examination of the data is most often conducted within the context of its use and within the situation in which the activity takes place (Yin, 1994). Second, variations in terms of intrinsic, instrumental and collective approaches to case studies allow for multiple sources of data collection. Third, the detailed qualitative accounts often produced in case studies not only help to explore or describe the data in the real-life environment, but they also help to explain the complexities of the phenomenon which may not be captured through experimental research (McDonough and McDonough, 1997). A case study approach can include a combination of documentation review, archival records, interviews, focus group discussions, direct observations, participant observation, and physical artefacts (Yin, 1994). Adding systems theory to case study research offers a more coherent picture to the phenomenon under investigation.

\section{SYSTEMS THEORY}

The relevance and applicability of systems theory are well established in healthcare research (Dooris, 2005). The principle of systems theory in healthcare research has been used to explore innovation, change and the complexity of service delivery and integration (Keating, 2000). The striking feature of systems theory is that it recognizes the 'system' as a whole, consisting of two or more parts (Bierema, 2003). These parts give rise to multiple relationships between those parts and these relationships affect each other over a period of time towards a common purpose (Bierema, 2003).

Systems theorists argue that the most important feature of a system is that it will no longer exist if it is split into parts and any alteration of one of the parts can influence a system's performance (Patton, 2002). The success of enhancing one part of a system will largely depend on the interaction between this part and the other parts of the same system (Rhydderch et al, 2004). For example, if one considers implementing new aspects of clinical care (such as physiotherapy and rehabilitation) into a well-defined, established setting (the organization), then one should also consider the interplay between the other parts within that system (for example, patients, staff, managers, resources, etc.) and how this might affect the whole system.

The advantage of using systems theory as part of the methodology is its usefulness in exploring a 'problem opportunity'. Therefore, systems theory is useful in directing this study to explore an 'opportunity' rather than a 'problem'. Systems theory centres on a premise that there is a theoretical concept (that is, the ideology and intentions of physiotherapy) and a practical one (that is, how can physiotherapy be integrated into the organization) (Ledington and Donaldson, 1997). It is the union between the two that provides the most comprehensive picture of the problem situation (or in this case, the opportunity situation).

Potential exists for aligning the case study with systems theory as the case is already regarded as a bounded system (Stake, 1995). According to Luck et al (2006), a case is a recognizable, complex and integrated purposive system. Thus, it is difficult to even attempt to describe the case without inadvertently describing the system as they are logically connected (Luck et al, 2006). However, in order to provide a focus for the application of case study-systems theory methodology, an example of case study and systems theory that have interrelatedness and interdependence with the cases is provided below. 
Interpretive Qualitative Case Study Aligned with Systems Theory for Physiotherapy and Rehabilitation Research

A CASE STUDY-SYSTEMS THEORY EXAMPLE

Exploring the Role of Physiotherapy in an Occupational Health Setting

An example of implementing physiotherapy in an occupational health setting is presented to demonstrate the effectiveness of aligning qualitative case study with systems theory (see figure 1). Occupational health physiotherapy is complex and in order to demonstrate the innovative, emergent role of physiotherapy in this setting, its interrelationship with the occupational health doctors and nurses (that is, the case) is integrated with the elements that have interdependence with the case (that is, the systems) so that a holistic perspective of physiotherapy's role in occupational health can be explored. Limiting the integration of physiotherapy only within the occupational health team (that is, the case) makes it less effective, whereas aligning it to systems theory illuminates physiotherapy's role within the service. This approach encourages physiotherapy to move away from professional isolation and into the real-world interrelationships of the service.

\section{CONCLUSION}

Potential exists for aligning the case study with systems theory as the case is already regarded as a bounded system (Stake, 1995). According to Luck et al (2006), a case is a recognizable, complex and integrated purposive system. The main challenge in aligning case study research with systems theory is defining the case. Systems theory requires the holistic exploration of relationships and interdependence in the case (Luck et al, 2006). Therefore, aligning case study with systems theory broadens the physiotherapy and rehabilitation framework, by combining the interrelationships of physiotherapy (that is, the case) with external interdependence influences of the service (that is, the systems).

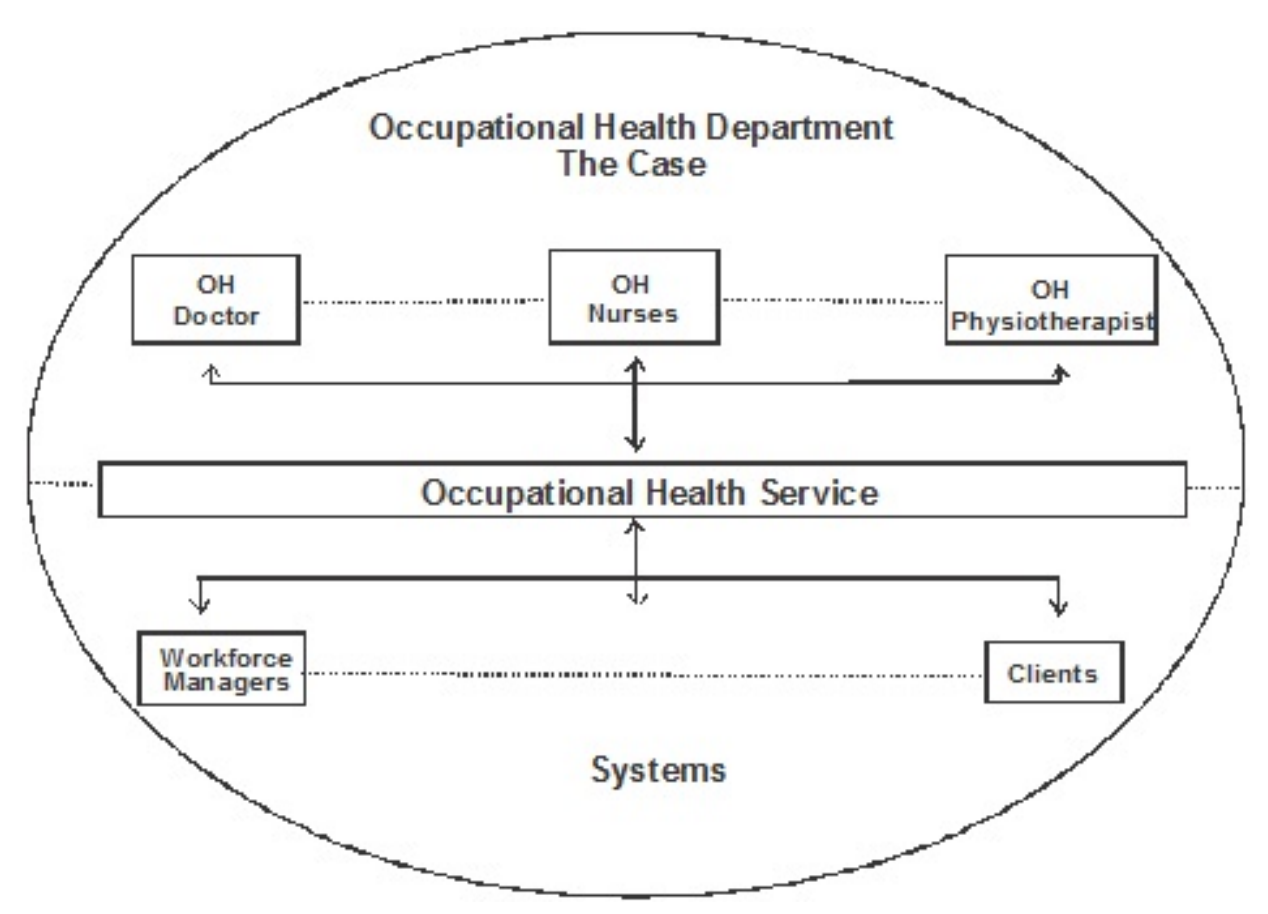

Figure 1. The case aligned with the system

\section{References}

Anaf, S., Drummond, C. and Sheppard, L.A. 2007. Combining case study research and systems theory as a heuristic model. Qualitative Health Research 17(10): 1309-1315.
Angen, M. 2000. Evaluating interpretive inquiry: Reviewing the validity debate and opening the dialogue. Qualitative Health Research 10(3): 378-395.

Bierema, J. 2003. Systems thinking: A new lens for old problems. The Journal of Continuing Education in the Health Professions 
23(1): 227-233.

Creswell, J.W. 2003. Research design: Qualitative, quantitative and mixed methods approach. $2^{\text {nd }}$ ed. Thousand Oaks, California: Sage Publications.

Darling, Y. and Scott, D. 2002. Qualitative Research in Practice Stories From the Field. Maidenhead: Open University Press.

Denzin, N.K. and Lincoln, Y.S. 2003. Introduction - the discipline and practice of qualitative research. In: Denzin, N.K. and Lincoln, Y.S. (eds.) Strategies of Qualitative Inquiry. Thousand Oakes: Sage.

Dooris, M. 2005. Healthy settings: Challenges to generating evidence of effectiveness. Health Promotion International 21(1): 55-65.

Flick, U. 2002. An Introduction to Qualitative Research. $2^{\text {nd }}$ ed. London: Sage.

Gergen, K. 2002. Second Opinion: An introduction to health sociology. $2^{\text {nd }}$ ed. South Melbourne: Oxford University Press.

Greene, J. 1992. The practitioner's perspective. Curriculum Inquiry 22(1): 39-45.

Gulsecen, S. and Kubat, A., 2006. Teaching ICT to teacher candidates using PBL: A qualitative and quantitative evaluation. Educational Technology and Society 9(2): 96-106.

Irvine, H.J. and Gaffikin, M. 2006. Getting in, getting on and getting out: Reflections on a qualitative research project. Accounting, Auditing and Accountability Journal 19(1): 115145.

Jones, M., Grimmer, K., Edwards, I., Higgs, J. and Trede, F. 2006. Challenges in applying best evidence to physiotherapy, The Internet Journal of Allied Health Sciences and Practice 4(3).

Keating, C. 2000. A systems-based methodology for structural analysis of health care operations. Journal of Management in Medicine 14(3): 179-198.

Ledington, P. and Donaldson, J. 1997. Soft and management practice: a study of the adoption and use of soft systems methodology. The Journal of the Operational Research Society 48(3): 229-240.
Lee, A.S. and Baskerville, R.L. 2003. Generalizing generalizability in information systems research. Information Systems Research 14(3): 221-143.

Luck, L., Jackson, D. and Usher, K. 2006. Case study: a bridge across paradigms. Nursing Inquiry 13(3): 103-109.

Manning, K. 1992. A rationale for using qualitative research in student affairs. Journal of College Student Development 33: 132-136.

McDonough, J. and McDonough, S. 1997. Research Methods for English Language Teachers. London: Arnold.

Neuman, W.L. 1997. Social Research Methods: Qualitative and quantitative approaches. $3^{\text {rd }}$ ed. Needham Heights, Massachusetts: Allyn and Bacon.

Parry, A. 1997. New paradigms for old: Musings on the shape of clouds. Physiotherapy 83(8): 423-433.

Patton, M.Q. 2002. Qualitative Research and Evaluation Methods. $3^{\text {rd }}$ ed. London: Sage Publications.

Rhydderch, M., Elwyn, G., Marshall, M. and Grol, R. 2004. Organisational change theory and the use of change indicators in general practice. Quality and Safety in Healthcare 13(3): 213-217.

Roulston, K., de Marrais, K. and Lewis, J. B. 2003. Learning to interview in the social sciences. Qualitative Inquiry 9(4): 643668.

Stake, R.E. 1995. The Art of Case Study Research: Perspective in practice. London: Sage.

Thorne, S., Kirkham, S. and MacDonald-Eames, J. 1997. Interpretive description: a non-categorical qualitative alternative for developing nursing knowledge. Research in Nursing and Health 20(2): 169-177.

Veenstra, G. 1999. Different worlds: Three approaches to health research. Canadian Journal of Public Health 90(1): 18-21.

Yin, R.K. 1994. Case Study Research: Design and methods. $2^{\text {nd }}$ ed. Beverly Hills, California: Sage Publications. 